\title{
Die verhouding Heilige Gees en geloof by Paulus
}

\author{
G M M PELSER
}

Wat is die verhouding Heilige Gees en geloof by Paulus? Of anders gestel, is dit Paulus se opvatting dat dit die Heilige Gees is wat die geloof by die gelowige wek, of het die Heilige Gees daarmee niks te maak nie? 'n Antwoord op hierdie vraag is nie so voor-die-hand-liggend nie, aangesien dit by 'n oppervlakkige eerste waarneming wil voorkom asof Paulus homself oor die saak weerspreek.

Die bedoeling van hierdie ondersoek is egter nie om alle gevalle na te gaan waar Paulus oor die gelowig-word van die gelowige handel nie, maar om die aandag slegs te bepaal by die uitsprake van Paulus waarin pneuma en pistis in noue relasie met mekaar gebring word. Dit beteken dus nie dat die resultaat van hierdie studie gesien moet word as die finale antwoord op ons vraag nie, maar slegs as ' $n$ bevinding met betrekking tot 'n paar eksplisiete uitsprake van Paulus oor die onderhawige saak.

Ons begin ons ondersoek by Galate 3:2, 5. Dit is welbekend dat die sentrale tema van die brief aan die Galasiërs die vraag is of 'n mens die geregtigheid kan verkry deur die wet te onderhou of deur die evangelie te glo. Op hierdie vraag antwoord Paulus met groot nadruk dat dit alleen verkry kan word deur in Jesus Christus te glo $(2: 15 \mathrm{v} \mathrm{v})$. In 3:1 v v stel hy dan onomwonde dat wie geregtigheid deur die onderhouding van die wet probeer verkry, weer teruggeval het in die sarks-bestaan en dat hulle lewe nie deur die Gees beheers word nie (vergelyk ook 5:16 v v en Romeine 8:1 v v). Die Galasiërs het met die Gees in hulle geloofslewe begin en moet einduit die Gees hulle lewe laat beheers en nie in die sarks-bestaan terugval nie (vers 3). Die vraag is nou: wanneer het hulle die Gees ontvang, vóór of ná die gelowig-word? Die antwoord hierop gee Paulus in vers 2 . Wat sê Paulus in hierdie vers?

Die b deel van die vers is opgebou uit twee parallelle frases naamlik eks ergōn nomou - eks akoés pisteôs. Dit is egter'n vraag hoe volkome parallel die twee frases met mekaar is. Dit is nie so duidelik en seker hoe die frase verstaan en in vertaling weergegee moet word nie. ' $n$ Vergelyking van die jongste vertalings van hierdie frase toon duidelik die verskil in benadering daarvan aan. Die Good News Bible gee dit weer met: "by hearing the gospel and believing it", terwyl die New English Bible vertaal met: "by believing the gospel message" en as alternatiewe aanbied: "by the message of faith" en "by hearing and believing". Die Gute Nachricht vertaal met: "weil ihr die Gute Nachricht gehört habt und auf Jesus Christus vertraut"; 
Jerusalem Bible met: "because you believed what was preached to you"; Phillips met: "by believing the message of the gospel" en Groot Nieuws met: "door te geloven in de verkondiging".

Die weergawe van die Good News Bible en Gute Nachricht wat akoès pisteós sien as twee gebeure-woorde waarvan die gebeure temporeel plaasvind in die volgorde waarin die woorde in die oppervlakte-struktuur voorkom, bots met 'n stelreël van die Griekse grammatika. Volgens hierdie reël gaan die gebeure wat deur die genitief in die oppervlakte-struktuur weergegee word wanneer twee gebeure-woorde in 'n genitief- konstruksie met mekaar gebind word, temporeel vooraf aan die ander. Word die kombinasie akoēs pisteōs dus as 'n verbinding van twee gebeure-woorde gesien, moet dit volgens die grammatiese stelreël getransformeer word as: mense glo, mense hoor. Logies kan dit natuurlik nie.

Die vertaling van die New English Bible en ander sien die kombinasie as objek plus gebeure-woord en neem $a k o \bar{e}$ dan as aanduiding van die inhoud van wat gehoor word, dit wil sê die evangelie-boodskap. ${ }^{2}$

Verskeie eksegete ken ook aan akoē in hierdie konteks hierdie betekenis toe, maar sien pisteōs daarby as 'n kwalifikasie van akoé en gee die kombinasie dan weer met: "geloofsboodskap". ${ }^{3}$ Hierdie interpretasie hou in dat in die betrokke frase nie sprake is van die geloof van die Galasiërs nie maar slegs van die koms van die geloofsboodskap na hulle toe, waarmee gepaard gegaan of waarop berus het die koms van die Gees en sy ontvangs deur die Galasiërs. Dan word ook nie, eksplisiet, gestel dat die gelowig-word van die Galasiërs temporeel voorafgegaan het aan die ontvangs van die Gees nie. Die probleem met hierdie benadering is dat hoewel dit grammaties volkome in orde is om hierdie kombinasie te verklaar as "geloofsboodskap" of "boodskap wat geloof wek", die frase waarvan dit deel uitmaak dan nie volkome parallel loop met die voorafgaande frase nie. In die frase eks ergōn nomou word ergōn deur nomou gekwalifiseer soos akoés deur pisteōs, maar ergōn is duidelik 'n gebeure-woord wat verwys na wat die gelowige by wyse van die onderhouding van die wet doen om die geregtigheid te verkry. Indien akoẽ pisteớs die geloofsboodskap aandui, dan handel die tweede frase nie oor wat déúr die Galasiërs gedoen is nie maar slegs oor wat vír hulle gebeur het. Die vertaling van die New English Bible behou wel die gedagte van wat die gelowige van sy kant af gedoen het, maar ook hiér is die frase dan nie meer volkome parallel met die voorafgaande nie. Daar is natuurlik geen wet wat vereis dat parallelle frases of konstruksies altyd volkome gelyk aan mekaar moet wees ook in hulle dieptestruktuur nie. Ons het in die Nuwe Testament 'n hele paar voorbeelde van so 'n semantiese ongelykheid in die dieptestruktuur.

Die vraag is nou: is dit onmoontlik dat hierdie twee frases, soos in 
hulle oppervlakte-struktuur, ook in die dieptestruktuur parallel met mekaar loop? Indien dit wel die geval is, dan beteken dit dat akoês as 'n gebeure-woord met pisteos as 'n objek bind. Pistis moet dan hier die betekenis hê van "geloofsinhoud", die geloofsboodskap, dit wil sê die fides quae creditur. ${ }^{4}$ Die betrokke frases sou dan weergegee kon word met: "het julle die Gees ontvang deur die wet te onderhou of deur die geloofsboodskap te hoor". Dat pistis verstaan kan word in die sin van die geloofsboodskap, is vir die Nuwe Testament nie vreemd nie. Ons hoef trouens nie verder te soek as die brief aan die Galasiërs self vir' $n$ voorbeeld hiervan nie. In Galate 1:23 het dit duidelik hierdie betekenis. Die beswaar teen hierdie interpretasie van die betrokke kombinasie mag wees dat $a k o e ́$ dan te min sê van die Galasiërs se reaksie op die evangelieverkondiging. Hierop kan ons antwoord dat dit nie onmoontlik is dat akoe hier meer beteken as "hoor" nie. Dit moet minstens ook die aksie van "gehoor gee" inhou.

Hoe die frase ookal verklaar en weergegee word, dit blyk uit die onmiddellike konteks en ook uit die voorafgaande perikoop duidelik dat die Galasiërs se reaksie op die evangelieverkondiging, dit wil sê hulle geloof in die evangelie, hier ter sprake is. Hieruit blyk verder dat Paulus wil sê dat die ontvangs van die Gees deur die Galasiërs daarop berus het dat hulle gelowig geword het. Temporeel gesien, beteken dit dat hulle die Gees ontvang het eers nádat hulle tot geloof gekom het. Hierdie feit word aan die einde van die perikoop nogeens onderstreep (3:14).

Die vraag is nou of Paulus homself nie weerspreek met uitsprake soos in I Korinte 12:3, 9; II Korinte 4:13 en Galate 5:22 nie. Blyk dit nie uit hierdie tekste dat Paulus duidelik daarmee rekening gehou het dat die Gees die geloof in die gelowige wek nie? Op die oppervlak mag dit so voorkom, maar ons moet die betrokke uitsprake aan 'n deeglike ondersoek onderwerp.

Ons kan I Korinte 12:9 uit die staanspoor buite rekening laat, want dit is uit die konteks duidelik dat ons hier nie met geloof in die ware sin van die woord te doen het nie. ${ }^{5}$ Paulus handel hier oor besondere gawes van die Gees (charismata), en hoewel dit nie duidelik is wat hy presies met hierdie pistis charisma bedoel nie, is dit gewis iets anders as geloof in die algemeen. Dit is waarskynlik' $n$ besondere geloof wat in staat stel om wonders te doen. "Pistis ist hier eine besondere Gabe neben anderen, also nicht der Glaube, sondern offenbar die Fähigkeit, Wunder zu tun, also verwandt mit den charismata iamatōn". ${ }^{6}$

In Galate 5:22 waar Paulus handel oor Christelike deugde wat hy beskryf as vrugte van die Gees, verskyn pistis sewende in die ry. Geloof in die teologiese sin van die woord is juis die basis waarop al hierdie deugde berus en kan daarom nie op dieselfde vlak as hulle ter 
sprake gebring word nie. Dit kan in hierdie konteks daarom gewis nie gaan om pistis in teologiese sin nie maar wel om pistis in etiese sin. Schlier sê tereg in hierdie verband: "Pistis ist hier, wie allgemein erkannt wird, nicht der theologische Glaube, sondern entweder die Treue oder das Zutrauen bzw. Vertrauen". ${ }^{7}$

In I Korinte 12:3 het ons wel nie pneuma en pistis of pisteuein in noue verbondenheid met mekaar nie, maar dit gaan duidelik hier om 'n vorm van belydenis dat Jesus Here is, wat hier gewoonweg uitgedruk word met eipein. Die vraag is nou of Paulus wil sê dat iemand nie tot die geloof kan kom dat Jesus die Here is nie en daarom ook nie tot geloof in Jesus kan kom nie, tensy die Heilige Gees hierdie geloof in hom wek. Dit is vir die doel van ons ondersoek nie nodig om op die totale eksegetiese problematiek van hierdie vers in te gaan nie. Dit is wel belangrik om daarvan kennis te neem dat dit in die konteks klaarblyklik gaan oor ekstatiese spreke. ${ }^{8}$ As 'n ekstatiese spreker nou die uitspraak anathema lêsous sou maak, kan hy hom nie daarop beroep dat hy dit onder leiding van die Gees doen nie. Wie deur die Gees gelei word, kan in ekstatiese spreke alleen uitroep: $\mathrm{Ku}$ rios Iésous, en word hy nie deur die Gees gelei nie, is hy nie by magte om so uit te roep nie. Die kriterium vir Gees-geïnspireerde rede is die inhoud van die spreke. Daaraan alleen kan vasgestel word of dit deur die Gees geïnspireer is. Deur te sê dat die Gees hierdie spreke inspireer, beteken egter nog nie dat Paulus hiermee wil sê dat dit die Gees was wat geloof in Jesus as Kurios gewek het nie. Hier word eenvoudig nie gehandel oor die rol van die Gees by die totstandkoming van die geloof nie. "Wird I Kr 12, 3 der Ruf Kurios Iêsous als Kriterium des Geistesbesitzes angegeben, soll so nicht die homologia des Glaubens auf das pneuma zurückgeführt werden, sondern angegeben werden, wodurch man pneumatische Ekstase von dämonischer unterscheiden kann." ${ }^{\prime \prime}$ Die onderskeiding van die geeste is wat vir Paulus hier op die voorgrond staan en daarom nie die belydenis van geloof in die gewone sin van die woord nie. Daar is in elk geval in hierdie vers niks wat in teenspraak is met ons bevinding op grond van Paulus se uitspraak in Galate 3:2 nie.

By II Korinte 4:13 is die saak problematies. Hier is pneuma en pistis onmiddellik aan mekaar gebind deur die konstruksie to auto pneuma tēs pisteōs. Die meeste eksegete interpreteer die kombinasie pneuma $t \bar{e} s$ pisteōs in die sin van die Gees as auctor, as bewerker van die geloof. Die oorgrote meerderheid van die jongste Bybelvertalings interpreteer die konstruksie egter nie so nie. Terwyl sommige van die Engelse vertalings nog iets van pneuma behou het in die weergawe: "spirit of faith", is daar vertalings wat dít nie eers gedoen het nie. Gute Nachricht vertaal byvoorbeeld in samehang met die sitaat uit die Skrif met: "das gilt auch für mich", Groot Nieuws met: "geloofshouding" en Phillips met: "our faith is like that . .." 
Is daar enige aanduiding in die konteks wat dit gebiedend maak dat ons to pneuma moet interpreteer as verwysend na die Heilige Gees? In die vorige hoofstuk het die Gees wel 'n oorheersende rol gespeel in die argumentasie van Paulus. In 4:1 word met tên diakonian tautên teruggegryp op diakonia tou pneumatos naamlik die verkondiging van die evangelie (3:8; vergelyk $4: 3)$, terwyl in $4: 7$ deur middel van ton thēsauron nogeens hierop teruggegryp word. Hoewel pneuma dus in hoofstuk 4:1-12 nie eksplisiet ter sprake is nie, is die wek wat die Gees in die verkondiging van die evangelie vervul, steeds op die agtergrond aanwesig. Daar is dus uit die konteks voldoende rede om te vermoed dat to pneuma in 4:13 wel na die Heilige Gees verwys. Die saak word egter bemoeilik deur auto in die konstruksie. Waarna verwys auto? Dit kan nie terug verwys na die onmiddellik voorafgaande nie, want daar was in 3:17 laas eksplisiet van pneuma sprake. Dit kan alleen vorentoe wys en moet daarom saamgelees word met kata to gegrammenon. ${ }^{10}$ Auto wil dus tot uitdrukking bring dat die pneuma waarna Paulus verwys, iets te make het met wat in die Psalm geskrywe staan. Die siteringsformule kata to gegrammenon wat slegs hier by Paulus voorkom, is nie onbelangrik in hierdie konteks nie. Ons het reeds daarop gewys dat die kata-formule met to auto $\mathrm{ktl}$ bind. Kata dui ook nie volkome gelykheid aan nie maar slegs ooreenkoms." Die ooreenkoms wat daar is tussen Paulus en sy medewerkers aan die een- en die Psalmis aan die anderkant, is dat hulle dieselfde gesindheid van geloof openbaar. Dit gaan om die geloof en hoe daar geglo word. In pisteuomen word die frase echontes $k t l$ verklaar. Pneuma tēs pisteōs wil dan iets sê van die karakter van hierdie geloof wat ook by die Psalmis te vind was: dit is 'n geloof wat die gelowige laat spreek. Pneuma is hier die gees eie aan die geloof. Bultmann sien daarom die saak reg as hy sê: "In dem Satze $2 \mathrm{Kr} 4,13$ bedeutet pneuma tēs pisteôs nicht den Geist, der den Glauben schenkt, sondern den Geist, wie er dem Glauben eigen ist. Im grunde bezeichnet pneuma hier die Art und Weise des Glaubens."12 Die konstruksie van vers 13 leen hom grammaties volkome vir hierdie interpretasie en so is dit dan ook deur die nuwe vertalings geïnterpreteer en weergegee.

Vir die byna tradisionele interpretasie, naamlik dat Paulus hier van 'n deur-die-Gees-geïnspireerde-geloof praat, word deur sommige eksegete na 'n oënskynlik parallelle konstruksie, naamlik pneuma huiothesias (Rom 8:15), as fundering verwys. Uit die konteks van Romeine 8:15 word gewoonlik aanvaar dat die Gees die bewerker is van die aanneming tot kinders, en van daar uit word dan gekonkludeer dat die konstruksie pneuma tēs pisteōs die Gees as auctor, as inspireerder van die geloof in die oog het. Afgesien van die feit dat ons nie ' $n$ bevinding ten opsigte van ' $n$ skynbaar parallelle konstruksie uit 'n totaal verskillende kontekstuele verband sonder 
meer beslissend vir 'n konstruksie in 'n ander konteks kan maak nie, hang daar selfs ' $n$ vraagteken oor die genoemde interpretasie van die konstruksie pneuma huiothesias. Dit is nie moontlik en ook nie die bedoeling om binne die bestek van hierdie ondersoek indringend in te gaan op die betekenis van pneuma huiothesias nie. Daar is egter in die konteks van Romeine 8:15 niks wat verbied dat die genoemde konstruksie so geïnterpreteer word dat die besit van die Gees die kenmerkende, die waarborg is dat die gelowige ' $n$ kind van God is nie. In Galate 4:6 waar kindskap en die Gees ook in noue verband met mekaar gebring word, blyk dit uit die konteks duidelik dat God vir Hom kinders aangeneem het deur sy Seun na die wêreld toe te stuur (vers 5). En omdat of op grond daarvan dat hulle sy kinders is, het God sy Gees in hulle harte gestuur (vers 6). ${ }^{13}$ In die lig hiervan sou die konstruksie pneuma huiothesias nie ons interpretasie van II Korinte 4:13 weerspreek nie, maar eerder die Pauliniese opvatting steun dat die Gees die gawe is wat op die geloof geskenk word en dus nie die geloof inspireer nie. ${ }^{14}$

Soos aan die begin van hierdie studie gesê is, is hierdie ondersoek beperk tot 'n paar uitsprake waarin Paulus pneuma en pistis in noue relasie met mekaar bring. Ons bevinding is dat Paulus in die betrokke gevalle nie die gedagte uitspreek dat die Heilige Gees die geloof inspireer nie. Dit staan wel vir Paulus vas dat die Gees in die gelowige kragtig werksaam is, en hiervan sou ons kon aflei dat die Gees wel die versterker van die voortgaande geloof is. Dat die Gees egter by die aanvangsgebeurtenis, naamlik die gelowig-word in die gelowige aanwesig is en geloofwekkend betrokke is, leer Paulus nie.

Vergelyk ons nou hierdie beskouing met die praktyk soos dit in Handelinge beskryf word, dan merk ons dat dit volkome daarmee ooreenstem. Hoewel die Heilige Gees as gawe, volgens die doopberigte in Handelinge, ten nouste met die doop verbind was, word nêrens gesê dat die Heilige Gees die geloof gewek het nie. Die bekering en doop van Kornelius en sy huis is miskien die enigste uitsondering. Ons kan egter met sekerheid aanvaar dat die woorde van Petrus in Handelinge 2:38 die praktyk weerspieël soos dit in die vroeë kerk aan die orde van die dag was: bekering (dit wil sê gelowig word) doop in die Naam van die Here Jesus - ontvangs van die Heilige Gees.

Impliseer die bevinding waartoe hierbo gekom is nou dat die gelowig-word van die gelowige uit en uit mensewerk is? Hierop kan ons antwoord met ' $n$ besliste nee! Die Nuwe Testament gee genoeg blyk daarvan dat die geloof ' $n$ genadegawe van God is (vergelyk Efese 2:8). Ook laat die Nuwe Testament en so ook Paulus geen twyfel daaroor nie dat die Heilige Gees wel ten nouste betrokke is by die verkondiging van die evangelie. Die Pinkstergebeure en die resultaat daarvan is voldoende bewys van hierdie feit. Paulus kan daarom, om 
slegs enkele voorbeelde te noem, die openbaring van die wysheid van God, wat die verkondiging van die evangelie oor Jesus Christus is, toeskryf aan die Gees, (I Kor 2:10) en van die evangelieverkondiging praat as die diakonia tou pneumatos (II Kor 3:8). Die Gees is dus wel deeglik by die gelowig-word betrokke as die verkondiger van die evangelie. En dit is juis die wyse waarop die evangelie verkondig word wanneer die Gees daarby betrokke is, naamlik dat dit geskied deur die krag van die Gees (I Kor 2:4, 5; I Tess 1:5), wat die geloof moontlik maak. Alleen wanneer die verkondiging só geskied, kan die verkondiging gehoor en geglo word vir wat dit werklik is: die Woord van God (I Tess 2:13).

Hierdie studie word aangebied met die wete dat dit nie die laaste antwoord is op die vraag waardeur dit geïnisieer is nie, en dit word daarom aangebied met die hoop dat dit verdere ondersoek sal stimuleer. Oor een saak is daar egter nie twyfel nie en dit is dat dit aangebied word met die hoogste waardering vir' $n$ leermeester, kollega en vriend by die herdenking van sy vyf en twintigste jaar as dosent aan die Universiteit van Pretoria, professor P S Dreyer.

1 Vgl J P Louw Semantiek van die Nuwe Testamentiese Grieks, Pretoria 1976, 107.

2 Soos bv in Romeine 8:16; Hebreërs 4:2; vgl W F Arndt \& F W Gingrich, $A$ Greek-English Lexicon of the New Testament, sv akoe.

3 So bv H Schlier, Der Brief an die Galater,' Göttingen 1965, ad loc; A Oepke, Der Brief des Paulus an die Galater,"2 Berlyn s.j., ad loc; $\mathrm{H} W$ Beyer, Der Brief an die Galater $^{9}$ (NTD), Göttingen 1962, ad loc.

4 So bv H Lietzmann, an die Galater," Tübingen 1971, ad loc; Ook P A van Stempvoort, De Brief van Paulus aan de Galaten ${ }^{3}$ (De Prediking van het N.T.), Nijkerk 1972, ad loc; gee akoēs as 'n gebeure-woord weer maar vertaal die kombinasie met "gelovig luisteren".

$5 \mathrm{Vgl} \mathrm{bv} \mathrm{H} \mathrm{Conzelmann,} \mathrm{Der} \mathrm{erste} \mathrm{Brief} \mathrm{an} \mathrm{die} \mathrm{Korinther,} \mathrm{Göttingen} \mathrm{1969,} \mathrm{ad} \mathrm{loc;}$ H-D Wendland, Die Briefe an die Korinther (NTD), Göttingen 1965, ad loc; C K Barrett, The first Epistle to the Corinthians, London s.j. (1968), ad loc; F W Grosheide, De eerste Brief aan de Kerk te Korinthe, ${ }^{2}$ Kampen 1957, ad loc; ea.

$6 \mathrm{H}$ Conzelmann, aw, $246 \mathrm{v}$.

7 aw, ad loc; so ook A Oepke, aw ad loc; P A van Stempvoort, aw ad loc.

$8 \mathrm{Vgl} \mathrm{bv} \mathrm{H}$ Conzelmann, aw, ad loc; C K Barrett, aw, ad loc; F W Grosheide, $a w$, ad loc; J Weiss, Der erste Korintherbrief, ${ }^{\circ}$ Göttingen 1970 , ad loc.

9 R Bultmann, Theologie des Neuen Testaments,' Tübingen 1968, 331, N.2.

$10 \mathrm{Vgl} \mathrm{H}$ Lietzmann, An die Korinther $I / I I,{ }^{3}$ Tübingen 1969, ad loc; H Windisch, Der Zweite Brief an die Korinther, 1970, ad loc; F W Grosheide, De tweede brief aan de Kerk te Korinthe,' Kampen 1959, ad loc.

11 So tereg F W Grossheide, II Korinthe, ad loc.

12 aw, 331, N.2; 'n opvatting waarmee F W Grosheide, II Korinte, ad loc. in hoofsaak saamstem. 